\title{
Problem of improving information technologies for managing agricultural enterprises in the context of macroeconomic instability and risks
}

\author{
Dmitrii Stozhko*, ang Olga Ergunova \\ Urals State University of Economics, 8 Marta/Narodnoy Voli Str. 62/45, 620144 Ekaterinburg, Russia
}

\begin{abstract}
The study provides an assessment of the state and prospects for the development of information management systems (IMS) of agricultural enterprises in the context of modern macroeconomic instability, uncertainty and risks. The features of agricultural production that affect the nature and efficiency of the IMS use are defined. A modern functional approach to IMS assessment in the context of electronic modeling of business processes in the agro-industrial complex is revealed. A convergent feature of the current stage of the IMS development, due to the nature of the current macroeconomic situation, is defined. The role of IMS in the development of risk-oriented management is clarified. The article describes the existing theoretical and methodological approaches to risk morphology, as well as the strengths and weaknesses of centralized and decentralized risk management systems. Special attention is paid to the "modernization" risks that are most closely related to the IMS development.
\end{abstract}

\section{Introduction}

The objective of the study is to assess the state and prospects of information management technologies development in the agricultural sector. The value of information management technology is to meet the information needs of business entities. For this purpose, many enterprises create specialized information management systems (IMS).

The information provided by them contains information about different aspects of the company's activities in different time periods and has the form of regular or special management reports. However, at the present time, characterized by growing macroeconomic instability and high risks, further development and improvement of the IMS is required. This is especially true for agricultural enterprises that solve the problem of food security in the country.

\footnotetext{
* Corresponding author: d.k.stozhko@mail.ru
} 


\section{Materials and Methods}

The research used the methods of structural-functional, program-targeted, comparative and hermeneutic analysis. The subject of research is the level of development and state of modern information management systems at enterprises, the object of research is the sphere of agro-industrial complex.

\section{Results of the study}

About half a century has passed since the appearance of the so-called information "expert management systems", knowledge and various technological processes ("DENDAL", "Mycin", "PROSPECTOL"). During this time, dozens of new "expert systems" for information management, its accumulation, digitizing and use have appeared: "CYRUS", "MEDIATOR", "CHEF", "PERSUADER", "CASEU", "JULIA", and others. But all of them are not very effective. "Experts" more often make management decisions not based on the recommendations of such systems, but intuitively [1].

The modern market of information technologies requires special attention from agricultural enterprises to their quality and opportunities for effective use. Moreover, agricultural production as an object of management has specific features:

- existence of a multi-layered economy and significant differences between them;

- collapse of the previously existing industrial, economic, and financial-economic relations between the agricultural organizations and the need to form them on a fundamentally different market basis;

- changes in the management system in organizations and the lack of competence of new owners in management issues;

- weak use of requirements for rational organization of production, planning, incentives, insufficient accounting and control;

- reducing the regulatory impact of the state on the processes of agro-industrial production;

- strict dependence of agricultural production on natural historical (first of all, natural and climatic) conditions;

- aggravation of the country's food and environmental security problems in the current crisis;

- strengthening of the need to restore the "vertical" and "horizontal" manageability of the agro-industrial complex by state bodies;

- growing need for the formation of progressive management structures, improvement of levers and incentives for state regulation of agricultural complex development and formation of a rational system of relations between property and business entities;

- inefficiency of the income distribution (primarily natural, land rent) in the sphere of agricultural economy;

- processes of capital and property concentration that occur without targeted strategic regulation by the state and society.

These features have a significant impact on the organization of management of agricultural enterprises as a whole, and on information management systems in particular. In this regard, information reengineering plays a special role as an enterprise's activity to modernize previously used technological solutions at certain objects or areas of work. Such reengineering is an important condition for modernizing the entire Russian economy in the conditions of growing instability, uncertainty, and risks. The fact that the "era of disorder" has already begun in August 2020 was officially announced by the experts of the Deutche Bank. Changing the nature of time also involves the search for new IMS, improvement of previous technologies, and reorganization of many types of enterprises' activities. For 
example, B. Gates has long raised the issue of transferring the processes of in-line replication of products to external agents. "The question may arise, why was it necessary to get involved with replication at all? - he writes. -Previously, without electronic processes, we simply had no choice. Today, the information tools have reached such level of perfection that it is quite possible to outsource replication" [2]. In fact, we are talking about new technologies (outsourcing, crowdsourcing, etc.)

This fact is all the more important for agricultural enterprises, since the market of innovative products used and created, including at agribusiness enterprises, is experiencing a real boom. There are also new directions of technological modernization: bioleptics, biomimetics, molecular nanomedicine, proteomics, etc. Under these conditions, agricultural enterprises must ensure the social security of consumers of their products, and their social responsibility for the introduced innovations should be significantly increased. This, in turn, imposes new requirements for the system of using information technologies in agricultural enterprises.

In general, the activities of agricultural enterprises to modernize IMS are determined by the "Strategy for the development of the information society in the Russian Federation for 2017-2030" and the "National technology initiative" (NTI) - a long-term program to create conditions for ensuring the leading positions of Russian companies in new high-tech markets that will determine the structure of the world economy in the future (2016).

A feature of the current stage of development and use of information technologies, due to the transition to a new technological order, is the convergence of such technologies as nano-, bio-, congo- technologies and the formation of a simplex of NBIC technologies.

If to imagine an agribusiness enterprise as a complex of IMS, a functional approach can be used $[3 ; 4 ; 5 ; 6]$. Then the entire complex of information technologies used by the enterprise is placed in the following table:

Table 1. Functional distribution of the enterprise IMS

\begin{tabular}{|l|l|}
\hline $\begin{array}{l}\text { Functions } \\
\text { of management }\end{array}$ & Enterprise information systems \\
\hline Planning & $\begin{array}{l}\text { AIS (accounting Information system); } \\
\text { APS (Advanced planning and supervisory control); } \\
\text { CPM (corporate performance management); } \\
\text { ERP-1 (enterprise resource planning); } \\
\text { ERP-2 (Optimization of enterprise resource and external } \\
\text { relations management); } \\
\text { MRP-1 (material resource planning); } \\
\text { MRP-2 (material resource planning) }\end{array}$ \\
\hline Organization & $\begin{array}{l}\text { APS (Advanced planning and supervisory control); } \\
\text { ERP-2 (Optimization of enterprise resource and external } \\
\text { relations management); }\end{array}$ \\
\hline Motivation & $\begin{array}{l}\text { ERP-2 (Optimization of enterprise resource and external } \\
\text { relations management); } \\
\text { CPM (corporate performance management); }\end{array}$ \\
\hline Control & $\begin{array}{l}\text { AIS (accounting Information system); } \\
\text { CPM (corporate performance management); } \\
\text { DSS (decision support system); } \\
\text { ERP-1 (enterprise resource planning); } \\
\text { MES (manufacturing execution system); } \\
\text { MRP-1 (material resource planning); }\end{array}$ \\
\hline
\end{tabular}

Key direction in the use of IT technologies is business process modeling. This is especially important for agricultural enterprises, whose activities are characterized by a number of features. 
Different information technologies are used for modeling business processes. The most common are DFD and IDEF [7; 8].

As it is seen from the above data, enterprises practically do not have such an important element of the IMS as an information system of risk management (warning). In the best case, the occurrence of risks is explained by the state of the external environment of the enterprise.

Thus, the role of the internal environment of the enterprise in the formation of macroeconomic uncertainty and, consequently, various kinds of risks still falls out of the field of scientific analysis.

In addition, reducing uncertainty to a measure or degree of awareness turns out to be speculative in the context of existing fuzzy set theory. According to it, the definitions of various quantitative parameters are approximate and relative. These parameters characterize individual goals and actions, but do not reflect the overall situation in which a particular system is found, since different phases of its life cycle may be characterized by different algorithms (dynamics), different (sometimes even opposite) goals and tasks, and ways to solve them.

Therefore, the characterization of uncertainty as an insufficient measure of knowledge about the conditions of activity, low degree of their predictability and foresight does little practical to overcome the uncertainty itself (the formation of certainty situation). However, insufficient information is not always the only reason for risks. Of particular importance here is the probability of a risk situation that may not be related to awareness. The business entity may be well informed but may not be able to take the necessary measures to prevent or reduce the risk. Conversely, the entity may not have sufficient information, but in a situation of risks that are not amenable to mathematical calculation, modeling, and foresight, this circumstance will not affect its activities in any way.

Studying probability, the American economist F. Night $(1885$ - 1972) considered the essence of probability as a manifestation of the multiplicity of possible scenarios. In particular, he proposed to distinguish its three types. He referred to the first type of probability as a priori probability. The second type is statistical one (calculated using mathematical methods). And the third type - "evaluating" (evaluated subjectively) [9].

In turn, the Russian economist E.E. Slutsky $(1880$ - 1948) considered probability as a possibility of breaking the system stability. He associated this possibility with the "substitution effect", the essence of which was to compensate for specific resources that ensure equilibrium [10]. This approach was quite justified, since in order to detail the risks faced by enterprises, it was necessary to design specific functional systems using functional modeling technology. At the present stage, such a functional modeling technology has already developed (SADT - structural analysis and design technology) and is an objectoriented graphical modeling in the form of a hierarchical multi-level modular system using top-down decomposition [11]. The use of functional modeling in risk research is most promising for describing the process approach and, consequently, the risk management process.

The modern system of risk stability of an enterprise should include several blocks at the same time: economic, organizational, theoretical and methodological, innovative and educational, and technological. This, in turn, requires a synergistic approach.

It is important to note that risks significantly reduce the stability of the entire system (both the economy as a whole and an enterprise in particular) and in a certain sense devalue the value of information technologies.

The concept of "sustainable development" appeared in the 70s of the XX century and was considered as a certain relationship between the human environment, the economy as a way of its development and the population as a subject of production and consumption. The meaning of this concept was precisely the theoretical and methodological justification of 
the possibility of sustainable development of socio-economic systems in conditions of risks, instability and uncertainty.

Currently, in the scientific field, three paradigms of risk classification have become widespread: circumstances, scale and forms of their manifestation.

The first approach is represented by the works of K.V. Baldin, A. Wasserman, S.N. Vorobyov, and M. Khazin. In particular, K.V. Baldin and S.N. Vorobyov believe that it is necessary to introduce two additional features into the risk classification system: the results of entrepreneurial activity and the risk formation mechanism. M. Khazin noted that in modern market conditions, enterprises cannot afford a longer planning horizon due to the fact that market demand for products may change, so losses may lead them to bankruptcy.

The second approach to risk classification is to use the method of accounting for threats by the scale of their manifestation. This approach is usually used by enterprises with knowledge-intensive production, such as enterprises related to energy, nuclear production, spaceports, airports, etc. Thus, the lack of consideration of any threats can lead to significant damage to the environment and people working at the enterprise, as well as to the population living near this place [12].

Due to the serious damage caused by under-accounting of possible risks, the probability of its occurrence should be minimal due to constant monitoring and constant measures aimed at thir prevention. In particular, researcher E.S. Wentzel believes that the more dangerous the possible prediction error, the closer to zero the probability of a negative event should be [13]. At the same time, the author highlights the following factors that must be considered when classifying a negative event:

- number of people at risk,

- amount of losses,

- area size,

- duration of symptoms,

- number of people at risk,

- amount of losses,

- area size,

- duration of symptoms,

- dynamics of changes in the level of losses over time.

When using this approach, there are problems in measurement. According to researcher $\mathrm{K}$. Burke, the most reliable risk assessments are quantitative and qualitative measurement scales [14].

The advantages of this approach include constant monitoring of the production process in order to avoid risks, a well-built risk system based on the synthesis of quantitative and qualitative methods for assessing possible threats. In addition, the method allows to clearly demonstrate the possible consequences, both in statics and dynamics. This method also allows to evaluate short -, medium- and long-term effects of possible risks and threats.

The disadvantages include: complex assessment system that requires a high level of professionalism from the staff, complexity of measuring quality assessments, and criteria for their development.

The third approach to risk classification is related to the forms of their manifestation. As it is said, "it is not the circumstances themselves that are important, but the meanings we give them. To assess possible threats, it is not always possible to use only the risk assessment method based on the scale of their manifestation to prevent various threats. For this reason, the method of risks classificatiob by their forms of manifestation is used. In this case, such a method is understood as the method of objective existence of risk and its impact on people's activities, which can be expressed in material, financial or moral form [15]. 
Material forms of losses are related to people, materials, equipment and machinery, time, etc. The moral forms of risks include image loss, loss of trust, good name, etc. Whereas financial losses include the loss of funds [16]. In this case, the company makes a rating map for possible losses. At the same time, risks can be assessed in accordance with the company's goals. For example, the most important criterion may be the loss of finances, then material and last of all image and reputation losses. Or vice versa: decrease in the company's capitalized value, outflow of highly qualified personnel, and loss of its market niche (market share).

The configuration of losses caused by risks is associated with the presence or absence of a creative approach to working with them. Such creativity in risk management sometimes means a variety of things. For example, the ability to see risk as an opportunity for new development, renewal, and success where previously it was or seemed impossible. No wonder people say, "nothing venture, nothing win." But sometimes creativity means adventurism. And, although the term itself has a constructive beginning (in the translation from the French avante - moving forward), it is well known that "work smart not hard. In other words, moving forward sometimes contradicts the very logic of the market economy development, when a new maneuver, temporary retreat and concentration of resources are required from the enterprise. Rushing forward in an unprepared situation is often equivalent to suicide (bankruptcy). Finally, a creative attitude to risks can also be considered as an opportunity to update the enterprise (company), to revise previous value orientations, for example, the job responsibilities of employees. R. Waterman notes that the development and use of "programs for independent employees serves as an official recognition of the fact that in the new conditions they are more important for the enterprise than before, turning their "lame ducks " into potential drivers - leaders and moderators of development [17]. B. Gates attributes this phenomenon to companies in general, considering that "risk is a natural element of business in the emerging industry" [2].

Currently, there are two risk management systems: centralized and decentralized. Their advantages and disadvantages are shown in table 2.

Table 2. Advantages and disadvantages of centralized and decentralized risk management system

\begin{tabular}{|l|l|l|}
\hline $\begin{array}{l}\text { Type of risk } \\
\text { management system }\end{array}$ & Advantages & Disadvantages \\
\hline $\begin{array}{l}\text { Centralized risk } \\
\text { management system }\end{array}$ & $\begin{array}{l}\text { There is a specialized structure for } \\
\text { risk assessment, systematic data } \\
\text { collection, risk assessment is carried } \\
\text { out centrally, according to a single } \\
\text { methodology, the assessment of } \\
\text { objective indicators increases, the } \\
\text { assessment of subjective indicators } \\
\text { decreases. Costs are reduced by } \\
\text { controlling all positions and } \\
\text { mutually accounting of reverse } \\
\text { independent assessment } \\
\text { can be offset by a large } \\
\text { set of factors, complexity } \\
\text { in monitoring changes } \\
\text { and delayed response to } \\
\text { possible }\end{array}$ \\
$\begin{array}{l}\text { positions. risks. } \\
\text { bureaucracy of the }\end{array}$ \\
\hline $\begin{array}{l}\text { Decentralized risk } \\
\text { management system }\end{array}$ & $\begin{array}{l}\text { Risk assessment is performed by } \\
\text { individual structural divisions based } \\
\text { on approved methods. Reducing the } \\
\text { cost of the bureaucracy, taking into } \\
\text { account specific factors that are } \\
\text { evaluated by departments that deal } \\
\text { with these issues on an ongoing } \\
\text { basis. Improving efficiency in } \\
\text { making management decisions. }\end{array}$ & $\begin{array}{l}\text { High level of subjective } \\
\text { assessment, excessive } \\
\text { reinsurance and then } \\
\text { excessive financing to } \\
\text { cover the risks. Difficulty } \\
\text { in obtaining summary } \\
\text { information, lack of } \\
\text { qualified specialists in } \\
\text { risk analysis. }\end{array}$ \\
\hline
\end{tabular}


When choosing a classification of risks that further develop into their management system, the company additionally faces the choice of an internal risk and threat control model. Currently, researchers distinguish two models of internal risk control: traditional and risk-oriented models [18].

The traditional risk management model is more based on the approaches of a decentralized system, since internal control is aimed at compliance with methods, programs, rules, rationing, etc. [19]. In other words, the basis of risk management in the company is the regulations adopted at the enterprise. The essence of the risk-based approach (RBA) is to understand what first prevents the company from achieving its goals, as well as to find the best way to avoid a negative development scenario.

The need to develop a risk-based management system is now officially recognized at the level of the country's top management [20].

In connection with the need for modernization of the agro-industrial complex, they identify "modernization" risks associated with innovative development, updating the situation, focusing on the future, and the emergence of new branches and industries. The nature of "modernization" risks is associated with the idea of autopoiesis - self-caused development and reproduction [21]. The meaning of this interpretation is that undulating socio-economic development is associated with information paradigms and represents their change of so-called "leaps" in development. These "leaps" are fraught with the threat of "modernization" risk, since too slow changes in the I-technologies themselves do not keep up with the development of production forces.

It is considered that "modernization" risks equally concern all members of society: both owners and employees [22]. However, it is suggested that "modernization" risks are characterized by a tendency to globalization [23].

The fact is that in the conditions of modern globalism, there is a process of universalization of many risks, regardless of where the production process is carried out and, accordingly, personnel management is carried out. There is even an assertion that the modern world is not controlled in any way, but self-regulates spontaneously [24].

\section{Conclusion}

In the context of these changes, further improvement of the IMS by agricultural enterprises is required. This is especially due to the formation of a fundamentally new type of society the "risk society" (W. Beck) and the steadily growing risks in the agricultural sector of the economy. In particular, the threat of global hunger, which was officially warned by D. Beazley, Director of the UN World Food Program, in the spring of 2020.

It seems that the best way to assess risks and work with them on the basis of INtechnologies can be done using:

- econometric approaches, such as vector autoregressions (VAR models), allowing to estimate the trajectory of an impulse (negative event), as well as understand the duration and probability of risk occurrence;

- determination of critical thresholds based on quantitative and qualitative assessments, which can also be obtained objectively and subjectively. Using statistical data, it is possible to synthesize the obtained estimates and identify threshold values of negative events that will be determined not only on a quantitative basis, but will also contain qualitative guidelines. Subjective estimates in this case can be obtained by experts interviewing;

- the results obtained on the basis of matrix approaches allow to create a risk map with a certain level of criteria and the probability of a negative event.

Such a systematic theoretical and methodological approach will allow to form a comprehensive and synergistic risk assessment methodology that can be flexibly adapted to 
the activities of a particular enterprise (organization), take into account its specifics, achieve goals, and effectively manage risks based on risk-oriented management.

\section{References}

1. T.V. Avdeenko, A.A. Aletdinova, Scientific and Technical Bulletin of the Saint Petersburg State Polytechnic University, 1, 7 (2017)

2. B. Gates, Business with the speed of thought. How to achieve success in the information age (2006)

3. E.S. Babaeva, Bulletin of the Volga State University n.a. V.N. Tatishchev, 17, 48 (2011)

4. E.Yu. Vinogradova, A.I. Galimova, Scientific and Practical Sonference Fundamental and applied research in the field of management, economy and trade, 168 (2017)

5. A.N. Kazakova, A.G. Fayzullina, Symbol of science, 1(13), 119 (2016)

6. K.A. Semyachkov, Yu.A. Moskalenko, Journal of Economic Theory, 1(15), 161 (2018)

7. Methodology of functional modeling IDEF0, Guiding document, Moscow, Gosstandart of Russia (2000)

8. O.S. Cheremnykh, S.V. Cheremnykh, Strategic corporate reengineering: a process-cost approach to business management, Moscow, Finance and Statistics (2005)

9. F. Night, Almanac: theory and history of economic and social institutions and systems, 5, 23 (1994)

10. E.E. Slutsky, Bulletin of Statistics, 12 (1992)

11. State standards of the USA and Russia: HACCP, in HACCP, Risk analysis and control point identification system, Moscow (2004)

12. A.S. Sosnin, P.Ya. Prygunov, Enterprise security management, Kiev, European University, 160 (2002)

13. E.S. Wentzel, L.A. Ovcharov, Probability theory and its engineering provisions, Moscow, Higher school (2000)

14. K. Burke, Dimensions: concept, theory, problems, edited by B.V. Biryukov, Moscow, Progress (1987)

15. V.N. Voitova, A.T. Zamlelaya, Journal of Russian entrepreneurship, 4(226), 80 (2013)

16. A.G. Badalova, K.P. Moskvin, Russian entrepreneurship, 7, 92 (2005)

17. P. Waterman, Renewal factor: how the best companies remain competitive, Moscow, Progress (1988)

18. F.S. Rastegaeva, I.P. Sakhirova, I.N. Knyazeva, Vestnik WSSUTM, 5, 137 (2015)

19. L.S. Malkova, Methods and models of risk-oriented internal audit of an industrial enterprise, Thesis. Cand. Ec. Sc. Saint Petersburg State University of Engineering and Economics (2011)

20. Official website of the President of Russia, Minutes of the Presidium of the Presidential Council for strategic development and priority projects dated 21.12.2016, No. 12, http://www.kremlin.ru/

21. N. Luman, Social system, Essay on general theory, Saint Petersburg, Nauka (2007)

22. W. Beck, Risk society, On the way to another modern, Moscow, Progress (2000)

23. V.I. Sharin, Social risks as threats to social status and protection from them, proceedings of the Ural State University of Economics, 6(50), 188 (2013) 
24. A.N. Chumakov, Age of globalization, 4, 3 (2018) 